\title{
Sexual health educational intervention in medical students
}

Mónica B. Aburto-Arciniega, ${ }^{1}$ Ricardo A. Escamilla-Santiago, ${ }^{2}$ Claudia A. Díaz-Olavarrieta, ${ }^{1}$ Germán E. Fajardo-Dolci, ${ }^{3}$ María E. Urrutia-Aguilar, ${ }^{4}$ Angélica Arce-Cedeño, ${ }^{1}$ Arely A. Mota-Sánchez ${ }^{1}$ and Rosalinda Guevara-Guzmán ${ }^{1 *}$

${ }^{1}$ Research Division; ${ }^{2}$ Department of Public Health; ${ }^{3}$ Director's Office; ${ }^{4}$ General Secretariat. Universidad Nacional Autónoma de México, Faculty of Medicine, Mexico City, Mexico

\begin{abstract}
Introduction: The National Autonomous University of Mexico Faculty of Medicine created the Adolescent Pregnancy Prevention Program, which is aimed at students. Objective: To determine the sexual-reproductive health profile of medical students through a diagnostic questionnaire and of those who participated in an educational intervention on sexuality (three modules). Method: First-year undergraduate students, schoolyear 2017-2018, participated. Students were considered to be trained when they took at least one module. Results: The questionnaire was answered by 1157 students, $21.9 \%$ participated in at least one module, $43.1 \%$ had initiated sexual activity and $25 \%$ received the educational intervention. Not having used a condom in their last intercourse was identified in $20 \%$, and a high prevalence of intercourse under the influence of alcohol was observed. Conclusions: It is important for specific sexuality competences to be promoted among those who will be doctors in the future.
\end{abstract}

KEY WORDS: Adolescent pregnancy. Educational intervention. Sexuality.

\section{Intervención educativa sobre salud sexual en estudiantes de medicina}

\section{Resumen}

Introducción: La Facultad de Medicina de la Universidad Nacional Autónoma de México creó el Programa de Prevención de Embarazo en Adolescentes, dirigido a estudiantes. Objetivo: Determinar el perfil de la salud sexual-reproductiva de estudiantes de medicina mediante un cuestionario diagnóstico y de quienes participaron en una intervención educativa de sexualidad (tres módulos). Método: Participaron estudiantes del primer año de la carrera, ciclo 2017-2018. Se consideró que el estudiante fue capacitado cuando cursó al menos un módulo. Resultados: Contestaron el cuestionario 1157 estudiantes, $21.9 \%$ participó en al menos un módulo, 43.1 \% había iniciado vida sexual y 25 \% recibió la intervención educativa. El 20 \% no usó condón en su última relación y se observó alta prevalencia de relaciones sexuales bajo el influjo de alcohol. Conclusiones: Es importante promover competencias específicas en sexualidad entre quienes serán los futuros médicos.

PALABRAS CLAVE: Embarazo adolescente. Intervención educativa. Sexualidad. 


\section{Introduction}

According to the World Health Organization, ${ }^{1}$ adolescence is "the period of life in which the individual acquires the reproductive capacity, shifts from the psychological patterns of childhood to adulthood and consolidates socioeconomic independence". With the acquisition of reproductive capacity, the possibility of conceiving an unplanned pregnancy is also acquired. Approximately 16 million adolescent females in the world are estimated to give birth every year in low and middle income countries.

In Mexico, the 2012 National Health and Nutrition Survey considers adolescents to be those subjects from 10 to 19 years of age; in our country, more than 22 million individuals are estimated to belong to this group. ${ }^{2}$ With regard to reproductive health, $90 \%$ of adolescents were reported to have knowledge about any contraceptive method and that condom is the most commonly used. The number of adolescents who had their first sexual encounter without protection has decreased: from $57 \%$ (2006) to $33.4 \%$ in females, although this is still a highly vulnerable group, not only because in the first sexual intercourse they can conceive a pregnancy, but for the reasons for not using a contraceptive method.

In the 2014 National Survey of Demographic Dynamics, $44.9 \%$ of sexually active adolescents aged 15 to 19 were reported to have declared not having used a contraceptive method during their first sexual encounter, ${ }^{3}$ which placed them at risk for an early pregnancy or for acquiring a sexually-transmitted infection (STI). In the 2018 report of this survey, women's level of education was also reported to be a factor that influences on reproductive behavior: ${ }^{4}$ in the 2015-2017 triennium, the overall fertility rate of women with some degree of primary education was 2.82 children per woman, while in women with secondary and higher education it was 1.75.

In this regard, the 2015 National Strategy for the Prevention of Pregnancy in Adolescents included health policies and lines of action to combat this problem and, among its transversal axes, comprehensive sexuality education was proposed..$^{5}$ Thus, educational institutions have a social responsibility to support efforts aimed at preventing adolescent pregnancy, a situation that in Mexico represents a serious public health problem due to the various social, economic and health implications it entails.

In response to this context, the Faculty of Medicine of the National Autonomous University of Mexico created the Adolescent Pregnancy Prevention Program (PPEA - Programa de Prevención del Embarazo en Adolescentes), aimed at medical undergraduate adolescent students, with the purpose to increase their knowledge in various sexual and reproductive health issues through an educational intervention. A research project was developed that would allow the performance of a diagnostic study (phase I) to determine personal, family or social factors related to sexual risk practices and unplanned pregnancies in adolescent students of the Faculty. With the results, the PPEA established a collaboration with the National Institute of Perinatology and the National Center for Gender Equity and Reproductive Health in order to design the specific pedagogical contents and teaching strategies that were implemented in an educational intervention (phase II). This document presents data characterizing the profile of the students who participated in the diagnostic study and who voluntarily received the educational intervention during the 2017-2018 school year.

\section{Method}

The population participating in the PPEA was composed of first-year medical students aged 17 to 19 years. The study was approved by the Research and Ethics Commissions of the institution (registry number FM-DI-028-2017). All the students included voluntarily agreed to participate after being informed on the purpose and dynamics of the research.

\section{Phase I. Diagnosis}

A 68-question self-administered questionnaire, the reliability of which had already been assessed, was applied. ${ }^{6}$ The explored dimensions were general information, family data (mother and father), information on sexuality and sexually-transmitted infections (STIs), knowledge about contraceptive methods and substance abuse.

\section{Phase II. Educational intervention}

Three educational modules on sexual and reproductive health were designed: correct placement of male and female condoms, prevention and risks of sexually-transmitted infections and use of hormonal contraceptives. The educational intervention was based on the pedagogical model of direct instruction, which combines the teacher's explanations and guidance with the 
student's practice and feedback, in order to teach procedural concepts and skills (course-workshop). ${ }^{7}$ The contents and teaching resources were structured based on the techniques described in the official Mexican standards and clinical practice guidelines, and were reviewed by specialists in the subject, psychologists and education experts. All materials (electronic presentations, videos, brochures, infographics) were designed with a visual code suitable for the adolescent population (image design, color palette, shape structure), in order to favor the identification and acceptance of the provided information. Some anatomical models of the female and male reproductive systems were used, as well as samples of contraceptive methods as support resources during the intervention.

The modules were taught by sexual and reproductive health trainers who collaborate in the PPEA. Each module had a duration of 90 minutes. The dissemination of the course was carried out through the institutional social networks or it was offered face-to-face, and the registration was carried out with an electronic appointment system (a maximum of 15 students per session). Knowledge was assessed in each module before and after the educational intervention, which consisted of a self-administered questionnaire with 10 closed questions of the nominal-polytomous type. ${ }^{8}$

\section{Statistical analysis}

Data analysis was performed with the statistical software Stata 13.0 (Stata Corp). Regarding phase I, qualitative variables were described with percentages, and quantitative variables, with means. As for phase II, the student was considered to be trained when he/she took at least one of the three modules of the educational intervention. Twenty-four variables of interest were selected from the diagnostic questionnaire in order to find differences between the students who were trained and those who did not receive the educational intervention (sociodemographic, related to their sexuality, communication with parents, use of contraceptives, substance abuse and history of STIs). The chi-square test was used for qualitative variables, and Student's t-test for independent samples was used for quantitative variables. Finally, for the pre- and post-intervention evaluation of each module of the workshop, a Shapiro-Wilk test was performed to assume score differences normal distribution; when the $p$-value was $<0.05$, the Wilcoxon test was used, and if the $p$-value was $>0.05$ Student's t-test for paired samples was used. Significant differences were considered to exist when the $p$-value for all tests was $<0.05$.

\section{Results}

In total, 1157 students aged between 17 and 19 years answered the phase I questionnaire; $70.2 \%$ (812) were females and $29.8 \%$ (345) were males. At the time of the interview, $20.1 \%$ (232) were 17 years old; $65 \%$ $(n=752), 18$ years; and $14.9 \%(n=173), 19$ years. The percentage of mothers of students who had their first pregnancy before 20 years of age was $18.5 \%(n=214)$; as for the parents, $10.4 \%(n=120)$ had their first child before 20 years of age. Other relevant data were that $43.1 \%(n=499)$ of the students had already initiated sexual activity and $1.1 \%$ (13) reported having suffered any STI sometime in their lives. In addition, $12.6 \%(n=146)$ referred smoking; $45.1 \%(n=522)$, having consumed alcohol; and 8.6 $\%(n=99)$, having used some type of drug (Table 1).

Regarding the profile characterizing the volunteer students who received the educational intervention, $21.9 \%$ $(n=254)$ of total population that answered the diagnostic questionnaire participated in at least one of the three modules of the workshop. Only $21.1 \%$ of females and $25.2 \%$ of males participated in the modules, with no gender-attributable differences being identified. Of the entire subset of students aged 17 years, only $23.7 \%$ joined the training, as well as $21.8 \%$ of those aged 18 years and $22.5 \%$ of those aged 19 ; no significant differences were found regarding age either. Some characteristics where statistical differences were found were the following:

- Initiation of sexual activity ( $p=0.011): 25.8 \%$ of those who had already initiated sexual activity at the time of the survey did enroll in at least one of the modules, in comparison with $19.6 \%$ of those who had not initiated it.

- Number of sexual partners within the last three months $(p=0.039): 19.6 \%$ of the students who had not had any sexual partner enrolled in any module in comparison with $23.1 \%$ of those who had had two or more sexual partners and $26 \%$ of those who had had only one.

- Anal intercourse ( $p=0.017): 31 \%$ of those who declared practicing it enrolled in one of the modules, in comparison with $21.3 \%$ of those who did not practice it at the time of the survey.

- Intercourse with people of the same gender $(p=0.001): 53.1 \%$ of the students who answered affirmatively enrolled in the course and $21.4 \%$ of those who answered negatively also did enroll.

- Talking about sexuality with friends $(p=0.048)$ : $23.3 \%$ of those who declared doing so enrolled 
Table 1. Profile of the students who received the educational intervention on sexual and reproductive health in at least one of the three modules that were offered

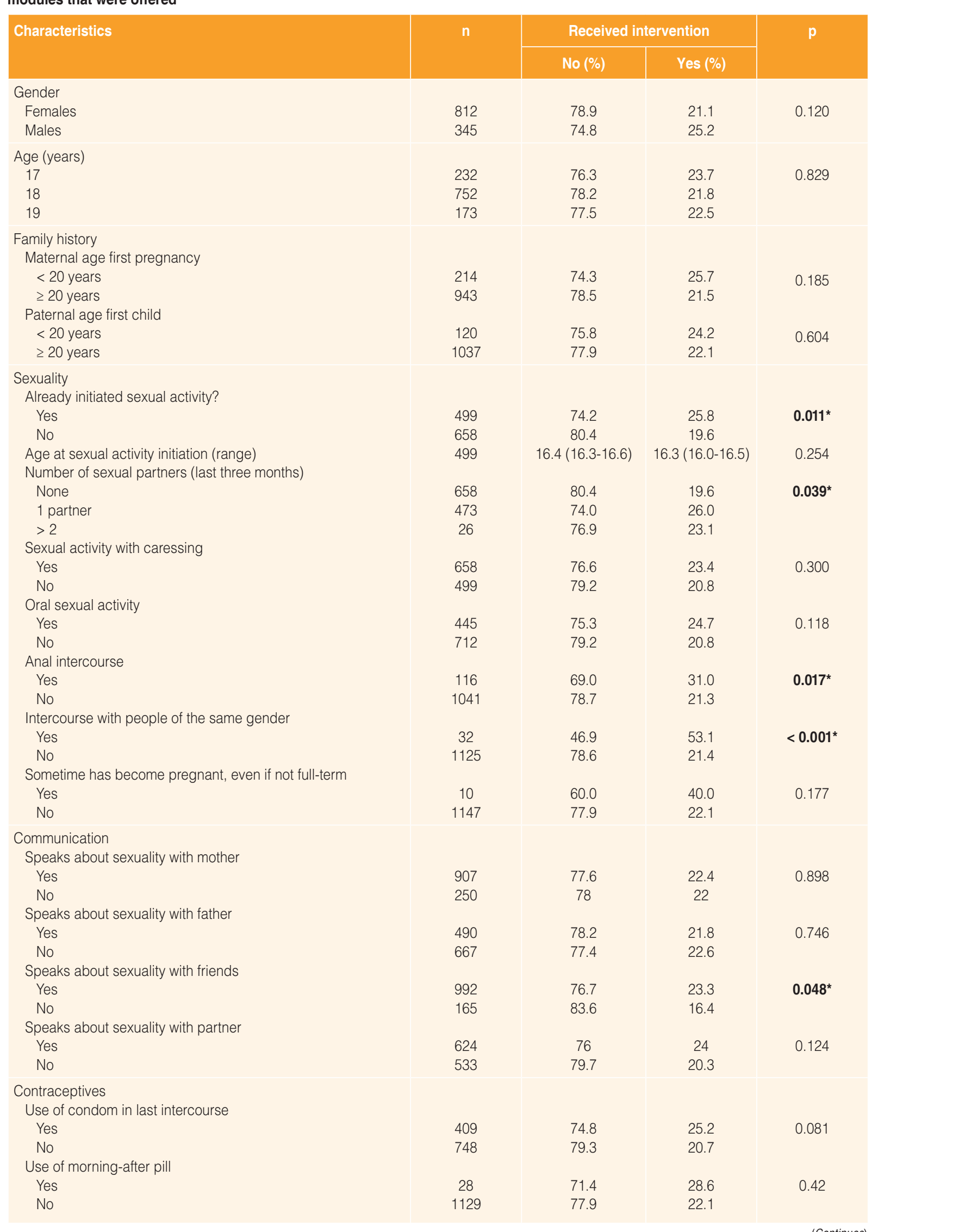


Table 1. Profile of the students who received the educational intervention on sexual and reproductive health in at least one of the three modules that were offered (Continued)

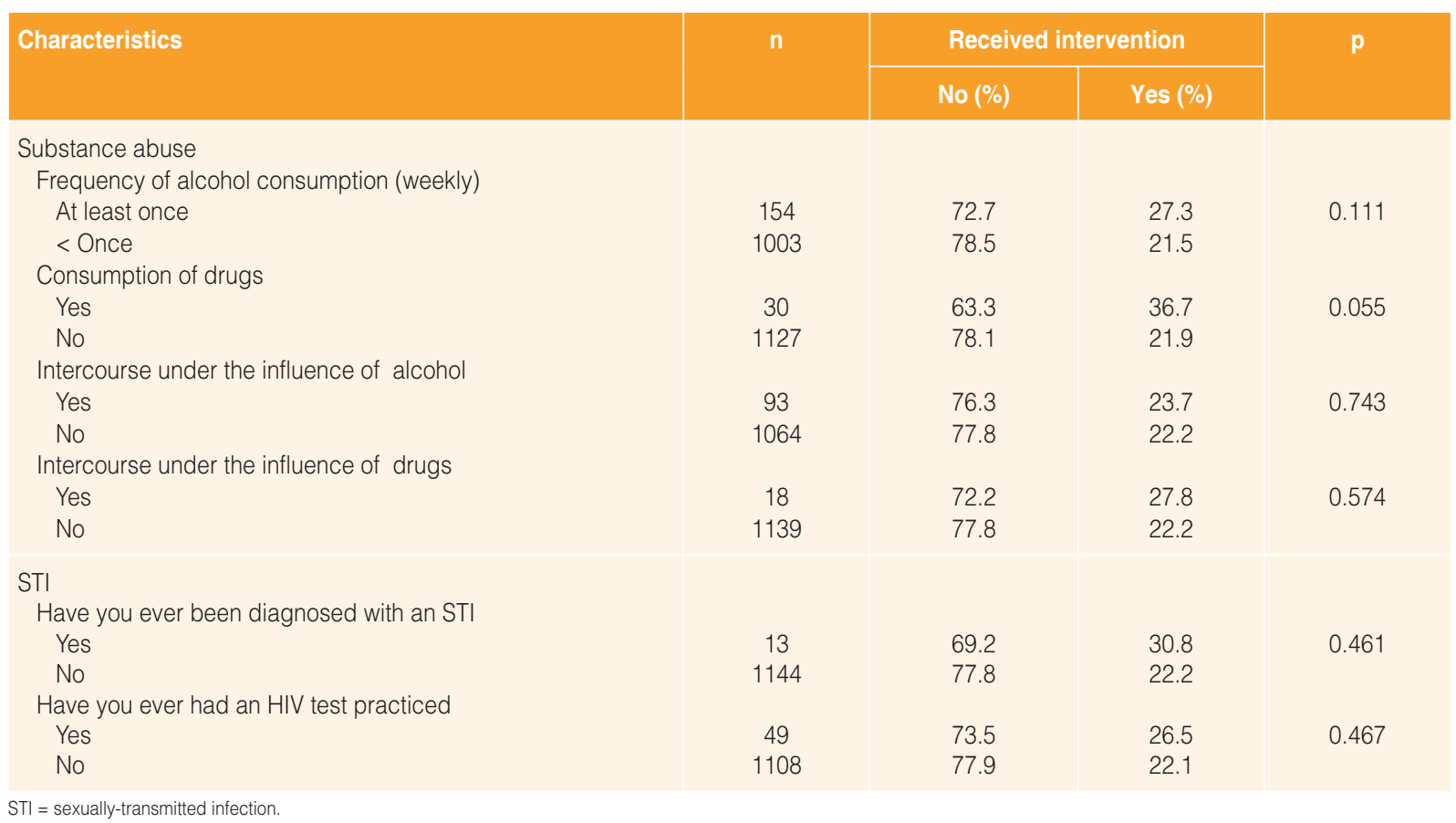

in one of the courses and only $16.4 \%$ of those who said they did not talk about that subject with friends did (Table 1).

Finally, of the 254 students who were trained in at least one of the three modules, 218 chose to take module $1 ; 109$, module 2 ; only 36 , module 3 . With the scores of the pre- and post-intervention assessments, statistical differences were found $(p<0.05)$ in all three modules (Fig. 1).

\section{Discussion}

Various national programs of sexual and reproductive health educational interventions have been documented in the national and international literature. In the study by Bennet and Assefi (2005), heterogeneity was reported in the implementation of the programs, as well as in the duration, objectives, subjects and strategies that are used. Although a change was documented in female adolescents' sexual behavior, the effects were moderate and, ultimately, possibly with a short-term impact. ${ }^{9}$ In the present study, evidence was obtained of an increase in the knowledge of the students who received the educational intervention, and the results provided a characterization of the college population interested in attending course-workshops on sexual and reproductive health issues. The profile allowed the group of researchers in charge of the PPEA to design an ad hoc intervention for vulnerable groups that might find themselves in risk situations, such as the students who referred not having used a condom during their last intercourse.

Although the PPEA does an important work at disseminating the courses that are offered, only $20.7 \%$ of the students who did not use a condom in their last sexual encounter attended a workshop. Females are currently the predominant population group in the Faculty of Medicine and who are exposed to higher reproductive risks, among which unplanned pregnancy is one of the most relevant.

Even when this was a population group where the prevalence of STIs is low (1.12\%), given that their average level of education is above the national mean, ${ }^{10}$ the fact that only $30.8 \%$ of participants with a history of STI diagnosis attended the module draws the attention. The figures are equally worrying regarding those who indicated having had an HIV test practiced $(4.23 \%)$, out of which less than one quarter were interested in any of the modules that make up the educational intervention.

We consider it relevant highlighting the prevalence of anal intercourse in a group of young people who mostly defined themselves as heterosexuals, with this practice being increasingly used and constituting a field of research that should be studied in depth. The trend that has been identified is that this practice is 


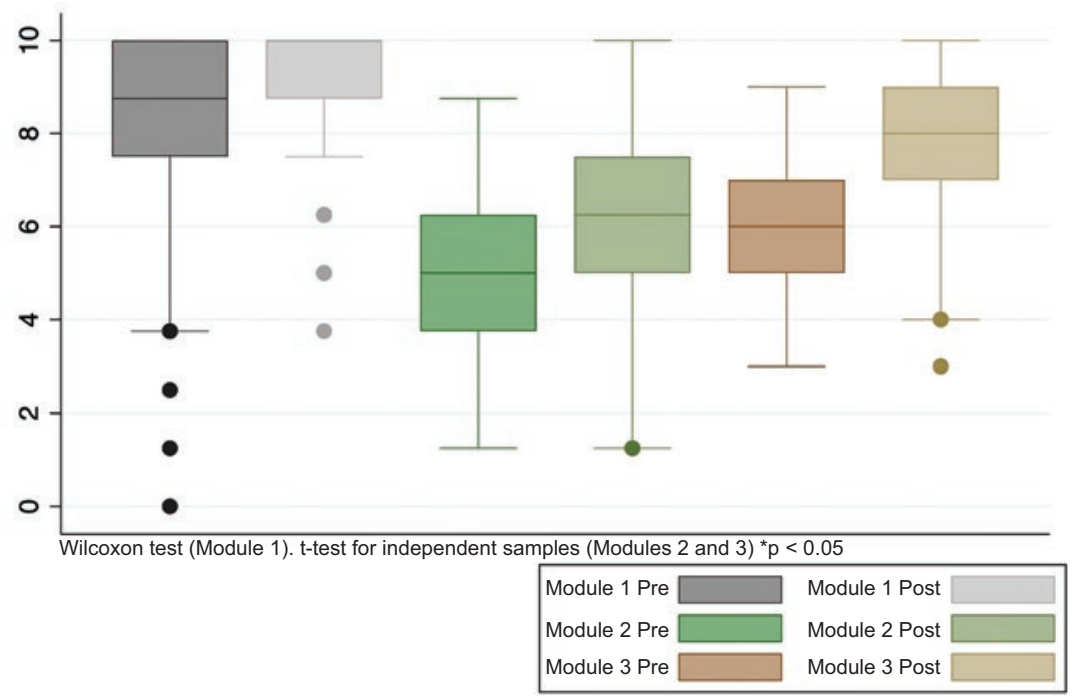

Figure 1. Scores obtained by 254 students who were trained in at least one of the three modules of a course-workshop on reproductive health; 218 chose to take module 1; 109, module 2; 36, module 3. With the pre- and post-intervention assessment scores, statistically significant differences $(p<0.05)$ were found in all three modules.

being chosen in order to avoid an early pregnancy and that the interest of this group in the intervention offered by our Program was in order to know the methods for protection against STIs.

Finally, the association between substance abuse (alcohol and drugs) and sexual intercourse among university students is documented in several investigations. ${ }^{11,12}$ In our study, we observed that the prevalence of students who have had sexual intercourse under the influence of alcohol was $8 \%$, which is higher than that related to sexual activity under the influence of any drug (1.5\%); therefore, the intersection of risk behaviors with adolescents' mental health should not be overlooked, which is a situation that is also duly taken care of by the PPEA, at least to refer them to the corresponding areas.

As previously described, national and international studies have documented that adolescents who have a lower education level or a low level of academic aspirations have higher fertility rates or are at higher risk for incurring a pregnancy situation. ${ }^{13,14}$ The educational intervention the PPEA has promoted for three years has shown positive effects on the increase of knowledge on sexual and reproductive health issues among the students who have participated, and it is therefore important to consider this strategy as part of the academic curriculum of the Faculty. This could favor the development of specific competences in the understanding of the different sexual practices, STIs, abortion, reproductive coercion and violence within the legal framework, among others. ${ }^{15}$ In addition to the impact on personal development, the PPEA might provide an additional long-term benefit to the general population, since the educational intervention considers the minimal conceptual elements the general practitioner should possess in matters of sexual and reproductive health.

\section{Conclusions}

There is still a great deal of work to do, and although the PPEA is a young initiative, the Faculty of Medicine of the National Autonomous University of Mexico has placed its bet on empowering adolescent students with a fundamental tool for the healthy development of their sex life and for adequate decision making: knowledge.

\section{Acknowledgements}

To María Gabriela Perera Salazar, for the development of the graphic language and identity of the teaching materials that were used in the educational intervention. To María Elena González Robles, for her collaboration with the graphic design and printing of materials for the dissemination of the course-workshop.

\section{Funding}

The Program for Support to Projects for Innovating and Improving Education granted the funding to carry out this research, registered with number PE215818. 


\section{References}

1. World Health Organization. Adolescent pregnancy. Suiza: World Health Organization/Department of Child and Adolescent Health and Development; 2018.

2. Instituto Nacional de Salud Pública. Encuesta Nacional de Salud y Nutrición. México: Instituto Nacional de Salud Pública; 2012.

3. Instituto Nacional de Estadística y Geografía. Encuesta Nacional de la Dinámica Demográfica. México: INEGl; 2014.

4. Instituto Nacional de Estadística y Geografía Encuesta Nacional de la Dinámica Demográfica. México: INEGl; 2018.

5. Consejo Nacional de Población Estrategia Nacional para la Prevención del Embarazo en Adolescentes. México: Conapo; 2015.

6. Aburto-Arciniega MB, Villa AR, Arce-Cedeño A, Escamilla-Santiago RA, Díaz-Olavarrieta C, Fajardo-Dolci G, et al. Contraceptive knowledge, substance abuse and unintended pregnancy among first-year medical students attending a public university in Mexico City. J Health Edu Res Dev. 2018;6:273

7. Magliaro, SG, Lockee BB, Burton JK. Direct instruction revisited: a key model for instructional technology. Educ Technol Res Dev. 2005:53:41-55.
8. Hernández B, Velasco-Mondragón HE. Encuestas transversales. Salud Publica Mex. 2000;42:447-455.

9. Bennett SE, Assefi NP. School-based teenage pregnancy prevention programs: a systematic review of randomized controlled trials. J Adolesc Health. 2005;36:72-81.

10. Instituto Nacional de Estadística y Geografía. Resultados definitivos de la Encuesta Intercensal 2015. México: INEGI; 2015.

11. Vázquez-Nava F, Vázquez-Rodríguez CF, Saldívar-González AH, Vázquez-Rodríguez EM, Córdova-Fernández JA, Felizardo-Ávalos J, et al. Unplanned pregnancy in adolescents: Association with family structure, employed mother, and female friends with health-risk habits and behaviors. J Urban Health. 2014;91:176-185.

12. Ayoola, AB, Brewer J, Nettleman M. Epidemiology and prevention of unintended pregnancy in adolescents. Prim Care. 2006;33:391-403.

13. Villalobos-Hernández A, Campero L, Suárez-López L, Atienzo EE, Estrada F, De la Vara-Salazar E. Embarazo adolescente y rezago educativo: análisis de una encuesta nacional en México. Salud Publica Mex. 2015;57:135-143.

14. León P, Minassian M, Borgoño R, Bustamante F. Embarazo adolescente. Rev Pediatr Electronica. 2008:5:42-51.

15. Shindel AW, Baazeem A, Eardley I, Coleman E. Sexual health in undergraduate medical education: existing and future needs and platforms. J Sex Med. 2016;13:1013-1026. 